\title{
Circulating Biomarkers of CDK4/6 Inhibitors Response in Hormone Receptor Positive and HER2 Negative Breast Cancer
}

\author{
Ilenia Migliaccio ${ }^{1, *}$, Angela Leo ${ }^{1}$, Francesca Galardi ${ }^{1}$, Cristina Guarducci ${ }^{2} \oplus$, Giulio Maria Fusco ${ }^{1}$, \\ Matteo Benelli ${ }^{3}$, Angelo Di Leo ${ }^{4}$, Laura Biganzoli ${ }^{4}$ (D) and Luca Malorni ${ }^{1,4}$ (D) \\ 1 "Sandro Pitigliani" Translational Research Unit, Hospital of Prato, Azienda USL Toscana Centro, \\ 59100 Prato, Italy; angela.leo@uslcentro.toscana.it (A.L.); francesca.galardi@uslcentro.toscana.it (F.G.); \\ giuliomaria.fusco@uslcentro.toscana.it (G.M.F.); luca.malorni@uslcentro.toscana.it (L.M.) \\ 2 Department of Medical Oncology, Dana-Farber Cancer Institute, Harvard Medical School, \\ Boston, MA 02215, USA; cristina_guarducci@dfci.harvard.edu \\ 3 Bioinformatics Unit, Hospital of Prato, Azienda USL Toscana Centro, 59100 Prato, Italy; \\ matteo.benelli@uslcentro.toscana.it \\ 4 "Sandro Pitigliani" Department of Medical Oncology, Hospital of Prato, Azienda USL Toscana Centro, \\ 59100 Prato, Italy; angelo.dileo@uslcentro.toscana.it (A.D.L.); laura.biganzoli@uslcentro.toscana.it (L.B.) \\ * Correspondence: ilenia.migliaccio@uslcentro.toscana.it; Tel.: +39-057-480-1110
}

check for updates

Citation: Migliaccio, I.; Leo, A.; Galardi, F.; Guarducci, C.; Fusco, G.M.; Benelli, M.; Di Leo, A.; Biganzoli, L.; Malorni, L. Circulating Biomarkers of CDK4/ 6 Inhibitors Response in Hormone Receptor Positive and HER2 Negative Breast Cancer. Cancers 2021, 13, 2640. https://doi.org/10.3390/ cancers 13112640

\section{Academic Editors:}

Eloisa Jantus-Lewintre, Rafael Sirera and Carlos Camps

Received: 26 April 2021

Accepted: 25 May 2021

Published: 27 May 2021

Publisher's Note: MDPI stays neutral with regard to jurisdictional claims in published maps and institutional affiliations.

Copyright: (c) 2021 by the authors. Licensee MDPI, Basel, Switzerland. This article is an open access article distributed under the terms and conditions of the Creative Commons Attribution (CC BY) license (https:// creativecommons.org/licenses/by/ $4.0 /)$.
Simple Summary: Biomarkers found in the blood of patients with hormone receptor positive and HER2 negative metastatic breast cancer are being investigated to understand how patients respond to treatments. Circulating biomarkers have the potential advantage of giving important information with a simple withdrawal of peripheral blood. Here, we review and discuss the recent achievements in the development of circulating biomarkers in patients with metastatic breast cancer treated with CDK4/ 6 inhibitors and endocrine therapy.

Abstract: CDK4/6 inhibitors (CDK4/6i) and endocrine therapy are the standard treatment for patients with hormone receptor-positive and HER2 negative (HR+/HER2-) metastatic breast cancer. Patients might show intrinsic and acquired resistance, which leads to treatment failure and progression. Circulating biomarkers have the potential advantages of recognizing patients who might not respond to treatment, monitoring treatment effects and identifying markers of acquired resistance during tumor progression with a simple withdrawal of peripheral blood. Genomic alterations on circulating tumor DNA and serum thymidine kinase activity, but also circulating tumor cells, epigenetic or exosome markers are currently being tested as markers of CDK4/6i treatment response, even though none of these have been integrated into clinical practice. In this review, we discuss the recent advancements in the development of circulating biomarkers of CDK4/6i response in patients with HR+/HER2-breast cancer.

Keywords: CDK4/6 inhibitors; circulating biomarkers; liquid biopsy; therapy resistance; breast cancer

\section{Introduction}

The majority of breast cancers (BC) (around 70\%) expresses hormone receptors (HR), either estrogen (ER) or progesterone (PR) receptors or both and is responsive to endocrine therapies (ET), including aromatase inhibitors (AIs), selective estrogen receptor modulators (SERMs) and selective estrogen receptor degraders (SERDs) like fulvestrant [1]. Women with early stage ER positive BC have a 20-year risk of distant recurrence ranging from $22 \%$ to $52 \%$, depending on the nodal status [2]. Currently, inhibitors of cyclin-dependent kinases 4 and 6 (CDK4/6i), namely abemaciclib, palbociclib and ribociclib, administered with ET, represent the standard for the treatment of patients with HR positive and HER2 negative (HR+/HER2-) metastatic breast cancer (MBC). Indeed, pivotal phase III randomized clinical trials [3-11] demonstrated the efficacy of the combination of CDK4/6i and AIs 
or fulvestrant in prolonging progression free survival (PFS) in the first- and second-line settings, which often translated into a benefit in overall survival (OS) as well [12-14]. In the early setting, a recent interim analysis of PALLAS, a multicenter phase III trial assessing the efficacy of adding two years of palbociclib to adjuvant ET, showed the lack of a significant improvement in invasive disease-free survival (IDFS), the primary endpoint of the study [15]. On the other hand, the multicenter phase III monarchE study demonstrated the superiority of the addition of adjuvant abemaciclib to ET in improving IDFS in patients with high-risk early disease [16].

Despite the significant improvements in survival determined by CDK4/6i in patients with $\mathrm{HR}+/ \mathrm{HER} 2-\mathrm{MBC}$, resistance represents a major clinical challenge. Resistance might present immediately after treatment initiation (de novo or primary resistance) or after evidence of initial clinical benefit (acquired or secondary resistance). Although a consensus on the definition of primary resistance to CDK4/6i is lacking, this may be defined as disease progression within 36 months of treatment initiation. Primary or de novo resistance occurs in about $15 \%$ of patients receiving CDK4/6i with AIs, and about $30 \%$ of those receiving CDK4/6i with fulvestrant. Additionally, acquired resistance develops in nearly all patients with $\mathrm{MBC}[17,18]$. One of the main goals of translational research in the CDK4/6i space is the identification of biomarkers of primary/de novo or acquired resistance to personalize therapeutic strategies.

In a population with MBC, collecting metastatic tissue before, during or after treatment is challenging due to the difficulties, potential side effects and patient uneasiness in obtaining a biopsy of the metastatic lesions. This might represent a shortcoming for biomarker discovery. In this population several circulating biomarkers, including circulating tumor DNA (ctDNA) and RNA (ctRNA), microRNA (miRNA), exosomes, proteins but also metabolites and circulating tumor cells (CTCs), are currently being investigated for their potential to identify patients with primary resistance, monitor the effects of treatments and also direct later therapies with a simple withdrawal of peripheral blood (Figure 1).

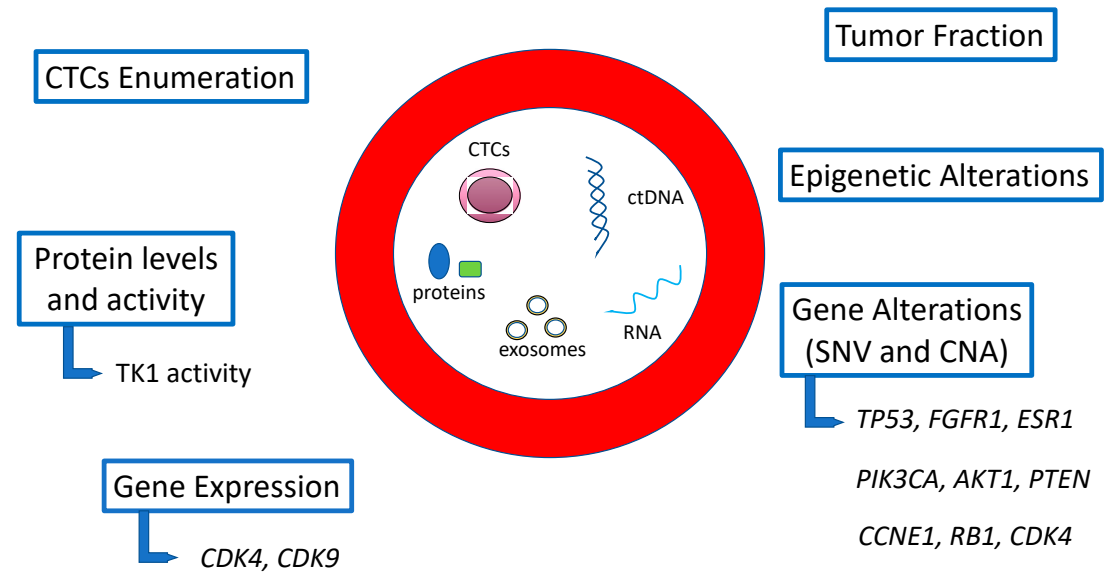

Figure 1. Schematic illustration of some of the potential circulating biomarkers of response to $\mathrm{CDK} 4 / 6 \mathrm{i}$ in HR+/HER2 - BC discussed in this review (TK1 = thymidine kinase 1; SNV = single nucleotide variations; $\mathrm{CNA}=$ copy number alterations).

A detailed and comprehensive review on biomarkers of CDK4/6i resistance has been recently published by our group [19]. In the present review, we focus on circulating biomarkers and highlight all studies and recent advancements on their potential clinical value in patients with CDK4/6i-treated HR+/HER2- MBC. Some of the studies described are yet to be published in full, but derive from pivotal clinical trials on CDK4/6i in $\mathrm{HR}+$ /HER2 $-\mathrm{BC}$ and have been presented in the form of abstracts at major international meetings. Table 1 illustrates the main clinical trials investigating CDK4/6i in HR+/HER2$\mathrm{BC}$, for which correlative studies on circulating biomarkers are available.

Table 2 illustrates the correlative studies from clinical trials on CDK4/6i in HR+/HER2$\mathrm{MBC}$ and the main circulating biomarkers. 
Table 1. Clinical trials on CDK4/6i in HR+/HER2- BC with correlative studies on circulating biomarkers.

\begin{tabular}{|c|c|c|c|c|}
\hline Name & Phase & Setting & Treatments & Results \\
\hline PALOMA-3 [4] & 3 & MBC II line & $\begin{array}{l}\mathrm{Pal} \text { and Ful } \\
\text { vs. } \\
\mathrm{Plb} \text { and Ful }\end{array}$ & $\begin{array}{l}9.2 \text { vs. } 3.8 \text { months PFS } \\
\text { HR } 0.42,95 \% \text { CI } 0.32-0.56\end{array}$ \\
\hline NEOPALANA [20] & 2 & Neoadjuvant & $\begin{array}{l}\text { Ana } \rightarrow \\
\text { Ana and Pal } \\
\rightarrow \text { Ana }\end{array}$ & $87 \%$ vs. $26 \%$ CCCA \\
\hline TREND [21] & 2 & $\mathrm{MBC} \geq \mathrm{II}$ line & $\begin{array}{c}\text { Pal } \\
\text { vs. } \\
\text { Pal and ET earlier line }\end{array}$ & $60 \%$ vs. $54 \%$ CBR \\
\hline PEARL [22] & 3 & MBC (AI-resistant) & $\begin{array}{c}\text { Cohort 1: } \\
\text { Pal and Exe } \\
\text { vs. } \\
\text { Cap } \\
\text { Cohort 2: } \\
\text { Pal and Ful } \\
\text { vs. } \\
\text { Cap }\end{array}$ & $\begin{array}{c}\text { Cohort } 2: \\
\text { 7.5 vs. } 10.0 \text { months PFS } \\
\text { HR } 1.13,95 \% \text { CI } 0.85-1.50 \\
\text { Cohorts } 1+2, \text { ESR } 1 \text { wt: } \\
\text { 8.0 vs. } 10.6 \text { months PFS } \\
\text { HR: } 1.11,95 \% \text { CI: } 0.87-1.41\end{array}$ \\
\hline MONARCH-2 [9] & 3 & MBC II line & $\begin{array}{c}\text { Abema and Ful } \\
\text { vs. } \\
\mathrm{Plb}+\mathrm{Ful}\end{array}$ & $\begin{array}{c}16.4 \text { vs. } 9.3 \text { months PFS } \\
\text { HR } 0.553,95 \% \text { CI } 0.449-0.681\end{array}$ \\
\hline MONALEESA-2 [6] & 3 & MBC I line & $\begin{array}{l}\text { Ribo and Let } \\
\text { vs. } \\
\text { Plb and Let }\end{array}$ & $\begin{array}{l}\text { NR vs. } 14.7 \text { months PFS } \\
\text { HR } 0.56,95 \% \text { CI } 0.43-0.72\end{array}$ \\
\hline MONALEESA-3 [10] & 3 & MBC I-II line & $\begin{array}{l}\text { Ribo and Ful } \\
\text { vs. } \\
\text { Plb and Ful }\end{array}$ & $\begin{array}{c}20.5 \text { vs. } 12.8 \text { months PFS } \\
\text { HR } 0.593,95 \% \text { CI } 0.480-0.732\end{array}$ \\
\hline MONALEESA-7 [11] & 3 & MBC I line & $\begin{array}{c}\text { Ribo and Tam or } \\
\text { NSAI and Gos } \\
\text { vs. } \\
\text { Plb and Tam } \\
\text { or NSAI and Gos }\end{array}$ & $\begin{array}{l}23.8 \text { vs. } 13.0 \text { months PFS } \\
\text { HR } 0.55,95 \% \text { CI } 0.44-0.69\end{array}$ \\
\hline
\end{tabular}

PFS = progression free survival; CCCA $=$ Ki67 $\leq 2.7 \%$ or complete cell cycle arrest; $\mathrm{CBR}=$ clinical benefit rate; HR = hazard ratio; $\mathrm{ET}=$ endocrine therapy; $\mathrm{Pal}=$ Palbociclib; Ribo $=$ Ribociclib; Abema $=$ Abemaciclib; Ful $=$ Fulvestrant $;$ Ana $=$ Anastrazole; Exe $=$ Exemestane; Let = letrozole; Tam = Tamoxifen; Gos = Goserelin; Plb = Placebo; Cap = Capecitabine; NSAI = Non-steroidal aromatase inhibitor.

Table 2. Correlative studies on circulating biomarkers for main clinical trials on CDK4/6i.

\begin{tabular}{|c|c|c|c|}
\hline Clinical trial & Correlative Studies & Methods & Main Circulating Biomarkers \\
\hline \multirow{5}{*}{ PALOMA-3 [4] } & O'Leary et al. [23] & Targeted panel & TP53, FGFR1, TF \\
\hline & Cristofanilli et al. [24] & ddPCR & PIK3CA \\
\hline & Fribbens et al. [25] & ddPCR & ESR1 \\
\hline & O'Leary et al. [26] & ddPCR & PIK3CA, ESR1 dynamics \\
\hline & O'Leary et al. [27] & Targeted panel & acquired mutations \\
\hline NEOPALANA [20] & Bagegni et al. [28] & Divitum & $\mathrm{TKa}$ \\
\hline \multirow{2}{*}{ TREND [21] } & McCartney et al. [29] & Divitum & TKa \\
\hline & Galardi et al. [30] & CellSearch & CTC \\
\hline MONARCH-2 [9] & Tolaney et al. [31] & ddPCR & PIK3CA, ESR1 \\
\hline \multirow{2}{*}{ MONALEESA-2 [6] } & Andre et al. [32] & Targeted panel & CHD4, ATM, FRS2, PRKCA, CDKN2A/2B/2C, AKT1 \\
\hline & Hortobagyi et al. [33] & Targeted panel & PIK3CA, TP53, RTK \\
\hline \multirow{2}{*}{ MONALEESA-3 [10] } & Andre et al. [32] & Targeted panel & CHD4, ATM, FRS2, PRKCA, CDKN2A/2B/2C, AKT1 \\
\hline & Neven et al. [34] & Targeted panel & PIK3CA, ESR1, TP53, FGFR1, CC, RTK \\
\hline MONALEESA-7 [11] & Andre et al. [32] & Targeted panel & CHD4, ATM, FRS2, PRKCA, CDKN2A/2B/2C, AKT1 \\
\hline
\end{tabular}

$\mathrm{TF}=$ tumor fraction; $\mathrm{TKa}=$ Thymidine kinase activity; $\mathrm{ddPCR}=$ droplet digital PCR; $\mathrm{CTC}=$ circulating tumor cells; $\mathrm{CC}=$ cell cycle associated genes; RTK = genes involved in receptor tyrosine kinase.

To date, studies failed to identify clear and strong predictive circulating biomarkers that might help discriminating patients with different benefits from CDK4/6i. However, 
some were able to identify markers that might predict poor outcome (i.e., prognostic markers) in patients treated with CDK4/6i.

\section{Biomarkers of Resistance to CDK4/6i on ctDNA}

CtDNA is part of the cell-free DNA and can be identified in the blood of the majority of patients with MBC [35]. It represents a source of tumor DNA that can be assessed for a variety of tumor genetic and epigenetic alterations [36]. Mutations, copy number variations and DNA-methylation alterations, but also the fraction of DNA deriving from the tumor (tumor fraction) as such might inform on tumor biology, disease extent and patients outcome [37].

In CDK4/6i-treated patients, ctDNA has been exploited to detect biomarkers of de novo resistance, to assess dynamics of genomic alterations during CDK4/6i administration and to evaluate biomarkers of acquired resistance at the time of tumor progression.

\subsection{Biomarkers of De Novo CDK4/6i Resistance on ctDNA}

$\mathrm{CDK} 4 / 6 \mathrm{i}$ mechanism of action is centered on Retinoblastoma protein $(\mathrm{Rb})$, the product of the retinoblastoma tumor susceptibility gene $(R B 1)$, which is the main target of the CDK4/6-cyclin D complex and has a critical role in cell cycle regulation [38]. Preclinical evidence suggests that alterations in RB1 or other cell cycle regulators such as amplification of cyclin E gene, CCNE1, may confer resistance to CDK4/6i [17,39-41]. Hence, alterations of genes involved in cell cycle regulation have been tested on ctDNA for their associations with outcomes in patients treated with CDK4/6i. Loss of RB1 (17.3\% of total patients) was associated with poorer PFS in patients treated with palbociclib and fulvestrant in PALOMA-3 trial [23]. Similarly, loss and/or loss of heterozygosity of cyclin-dependent kinase inhibitor 2A (CDKN2A) (22\% of total patients) and copy number gains in CDK4 and CCNE1 (both present in $<5 \%$ of patients) were associated with worse prognosis. These associations were significant at univariate, but not multivariate analysis, and no interaction with treatment was found. However, associations between loss of RB1 and gains in CCNE1 or CDK4 and PFS were observed in the palbociclib and fulvestrant, but not in the placebo arm [23]. In a combined analysis of three different phase III randomized trials of ribociclib plus ET, namely the MONALEESA-2, -3 and -7 , ctDNA obtained before treatment from 1503 patients was analyzed by next generation sequencing with a targeted panel containing 557-genes [32]. Patients with RB1 wild-type ctDNA tended to have more PFS benefit from ribociclib compared to patients with RB1-mutant ctDNA (1.7\% of total) [32]. In addition, patients with alterations in $C D K N 2 A / 2 B / 2 C$ ( $2.3 \%$ of total tumors) derived limited benefit from the addition of ribociclib to ET [32]. A trend towards limited benefit from ribociclib was observed in patients with alteration in cell-cycle related genes in the MONALEESA-3 trial [34]. BioItaLEE (NCT03439046) is a single-arm, phase IIIb trial of patients with MBC receiving ribociclib and letrozole as first-line. The trial analyzed ctDNA alterations before starting treatment and assessed their associations with clinical outcome [42]. Alterations within the CDK4/6-Rb pathway genes, including CDK4 and 6, CCND1, CDKN2A and $R B 1$, were associated with early progression [42]. All these data highlight the potential for alterations in genes within the CDK4/6-Rb pathway to serve as circulating biomarkers of palbociclib resistance. However, more data are needed to establish their clinical utility.

Phosphatidylinositol-4,5-bisphosphate 3-kinase, catalytic subunit alpha (PIK3CA) is the most frequently altered gene in HR+/HER2- MBC [43]. Preclinical studies suggest the phosphatidylinositol 3-kinase (PI3K)/mammalian target of rapamycin (mTOR)/protein kinase B (PKB, AKT) pathway might have a role in CDK4/6i resistance [39,44-47]. Thus, several studies analyzed ctDNA alterations within the PI3K pathway and their association with response to CDK4/6i. Mutations in PIK3CA were found in ctDNA of 33\%, 35\%, $33 \%$ and $40.3 \%$ of patients in the PALOMA-3 [24], MONALEESA-3 [34], MONALEESA2 [33] and MONARCH-2 [31], respectively. CDK4/6i similarly prolonged PFS in patients with PIK3CA mutated or wt ctDNA, suggesting the lack of a role for baseline PIK3CA mutations in predicting benefit from CDK4/6i. On the other hand, the prognostic role in 
patients treated with CDK4/6i remains unclear. Indeed, patients with PIK3CA-mutant and -wild-type (wt) tumors treated with palbociclib and fulvestrant within PALOMA-3 showed similar PFS (median PFS of 9.5 and 9.9 months, respectively) [24], while among patients receiving ribociclib and fulvestrant within MONALEESA-3, those with PIK3CA-mutant ctDNA showed numerically shorter PFS compared to PIK3CA-wt (16.4 vs. 22.3 months, respectively) [34]. Similarly, in MONALEESA-2 patients receiving ribociclib and letrozole with PIK3CA-wt, ctDNA had a median PFS of 29.6 months compared to 19.2 in those with PIK3CA-mutant [33]. The tumor suppressor phosphatase and tensin homolog (PTEN) is a negative regulator of the PI3K signaling. Loss of PTEN and AKT1 amplification or $A K T 1$ activating mutations in tumor samples have been associated with resistance to CDK4/6i $[48,49]$. Consistent with these data, loss of PTEN in ctDNA was associated with worse PFS in patients treated with palbociclib and fulvestrant within PALOMA3 [23]. On the other hand, in the MONALEESA-2 -3 and -7 pooled analysis patients with $A K T 1$ alterations, particularly $A K T 1$ E17K, showed increased benefit from ribociclib over placebo [32]. Alterations of PTEN and $A K T 1$ might also be relevant for therapeutic strategies subsequent to CDK4/6i, since PTEN loss might mediate resistance to PI3K $\alpha$ inhibitors $[50,51]$ and the AKT inhibitor capivasertib demonstrated clinical activity in AKT1 E17K-mutant MBC [52].

Additional alterations that have been tested on ctDNA for their association with outcome include those in the estrogen receptor (ESR1), fibroblast growth factor receptor 1 (FGFR1) and tumor protein 53 (TP53) genes. Mutations in ESR1 are frequently acquired in $\mathrm{HR}+/ \mathrm{HER} 2-\mathrm{MBC}$ following ET, particularly AIs [53]. ESR1 mutations were detected in $25.3 \%, 14 \%$ and $64.4 \%$ of plasma samples from patients enrolled in PALOMA-3 [25] MONALEESA-3 [34] and MONARCH-2 [31] trials, respectively. In PALOMA-3, they did not predict a benefit from palbociclib [25]. In MONALEESA-3, there was a trend toward increased PFS benefit from ribociclib vs. placebo for patients with ESR1-mutant tumors [34], and in MONARCH-2, there was a numerically greater benefit from abemaciclib plus fulvestrant in patients with ESR1-mutant tumors [31]. Results from the PEARL, a phase III multicenter study, have recently been published [22]. In this study, patients with HR+/HER2 - MBC resistant to AIs were randomized to receive palbociclib and exemestane vs. capecitabine (cohort 1). After the discovery that ESR1 mutations might be responsible for resistance to AIs, it was amended to include cohort 2, randomizing patients to palbociclib and fulvestrant vs. capecitabine. The trial demonstrated the non-superiority of palbociclib and ET vs. capecitabine in both cohorts [22]. The prognostic role of ESR1 in patients receiving CDK4/6i is yet to be established as well. Median PFS for patients receiving fulvestrant and palbociclib in PALOMA-3 did not differ according to ESR1 status (9.4 months and 9.5 for ctDNA ESR1-mutant and wt, respectively) [25]. In MONARCH-2, patients with ESR1-mutant ctDNA receiving abemaciclib and fulvestrant demonstrated a median PFS of 21.9 months vs. 16.3 of those with ESR1-wt [31], while in MONALEESA-3, patients receiving ribociclib and fulvestrant had median PFS of 9.3 and 22.3 months for ESR1-mutant and -wt ctDNA, respectively [34]. However, MONALEESA-3 analysis was presented irrespective of the line of treatment, and ESR1 mutations were more frequently observed in patients receiving treatment with ribociclib as second line compared to first line (24.6\% vs. $4.3 \%$, respectively) [34]. PADA-1 trial (NCT03079011) is a phase III trial evaluating the utility of monitoring ctDNA for the onset of ESR1 mutations in patients receiving palbociclib plus AIs in first line [54]. The prognostic impact of ESR1 was recently presented. Of 1017 patients analyzed, 33 had detectable circulating mutations in ESR1 at inclusion (3.2\%) and showed a significantly shorter PFS [54].

Altered FGFR-1 signaling was shown to mediate CDK4/6i resistance [55]. In PALOMA3, baseline FGFR1 gain on ctDNA was found to be associated with worse PFS in both the palbociclib and fulvestrant and the placebo and fulvestrant arms [23]. Associations remained significant at a multivariate analysis, but no interaction with treatment was found [23]. In MONALEESA-2, patients treated with ribociclib plus letrozole with FGFR1 amplification on ctDNA ( $5 \%$ of total patients) experienced shorter PFS compared to those with FGFR1-wt 
ctDNA [55]. However, in MONALEESA-3 and MONALEESA-2, the benefit from ribociclib was observed regardless of ctDNA FGFR1 alterations found at baseline $[33,34]$. These data point toward a prognostic rather than predictive role of FGFR1. Similarly, TP53 alterations seem to identify patients at risk of early progression regardless of CDK4/6i treatment. Indeed, in both PALOMA-3 and BioItaLEE, baseline ctDNA TP53 alterations were associated with significantly shorter PFS [23,42], but in PALOMA-3 associations with PFS were found in both palbociclib and placebo arms, and no interaction with treatment was found [23]. Additionally, in MONALEESA-3 and MONALEESA-2, ribociclib benefit was observed independently of TP53 alterations [33,34].

Tumors often harbor multiple gene alterations; therefore, evaluating the correlations between a single genomic alterations and response to CDK4/6i might be challenging. Additionally, estimation of copy number variations, particularly loss, on ctDNA is technically challenging. This, coupled with the low prevalence of some alterations such as $R B 1$ in $\mathrm{HR}+$ /HER2 $-\mathrm{BC}$, might make associations with patients outcome and interaction with treatment difficult to establish. In PALOMA-3, authors have focused on circulating tumor fraction assessment to identify patients with poor outcome [23]. They found that tumor fraction was associated with adverse PFS in both palbociclib and placebo arms and was independently associated with outcome at the multivariate analysis. Intriguingly, at the multivariate analysis, among all alterations found to be associated with PFS, only TP53 alterations and FGFR1 gain maintained an independent prognostic role [23], suggesting that tumor fraction might be a confounding factor during the evaluation of circulating biomarkers on ctDNA.

\subsection{Dynamics of ctDNA Biomarkers}

Other than assessing baseline biomarkers, an alternative strategy for predicting patients outcome might be to monitor early changes in selected markers. Circulating biomarkers are particularly helpful to this end for their ease to be repeated over time.

In PALOMA-3, PIK3CA and ESR1 mutations were analyzed both at baseline and after 15 days of palbociclib plus fulvestrant treatment [26]. After 15 days, relative changes from baseline in PIK3CA mutation levels were strongly predictive of PFS, while changes in ESR1 mutations were of limited prediction [26]. However, only $22 \%$ and $25.6 \%$ of patients analyzed in this study had PIK3CA and ESR1 ctDNA mutations, respectively [26]. To bypass this problem, in the ALCINA study (NCT02866149), 25 HR+/HER2- MBC patients receiving palbociclib and fulvestrant were assessed for ctDNA by droplet-digital PCR (ddPCR) based on somatic mutations found on their primary or metastatic tissue that could be tracked in circulating DNA, the majority being found in PIK3CA $(n=21)$, but also in TP53 $(n=2)$ and AKT1 $(n=2)$ genes [56]. At baseline, $84 \%$ of patients had detectable ctDNA levels, but these were not prognostic. Clearance of ctDNA observed at day 30 was associated with longer PFS, while an increase of ctDNA levels at day 30 compared to baseline was predictive of shorter PFS. Of note, in this study, dynamics at day 15 had no prognostic impact [56]. To overcome the need of prioritizing mutations based on tumor tissue genomics, Martínez-Sáez and colleagues sequenced plasma samples from 45 patients with CDK4/6i-treated HR+/HER2- MBC using the standardized Guardant360 assay [57]. Of these, $43(96 \%)$ had ctDNA detectable at some level. Authors found that the mean variant allele fraction ratio (mVAFR), calculated between the first day of cycle 2 and baseline, was significantly associated with PFS. However, they found no association with baseline and on-treatment VAF or absolute changes in VAF [57]. The different populations and methodologies and the lack of a univocal definition of tumor fraction might explain at least in part the different results across the studies.

\subsection{Circulating Biomarkers of Acquired Resistance on ctDNA}

In $\mathrm{MBC}$, acquired resistance to CDK4/6i and ET near-inevitably occurs. At the time of progression tumors might acquire new genetic alterations that can be analyzed on ctDNA samples. Analysis of these alterations might potentially help in deciphering the resistance 
mechanisms and also directing subsequent therapies. In PALOMA-3, analyzing paired ctDNA from baseline and end-of-treatment samples from 195 patients by target sequencing, newly acquired mutations in RB1, PIK3CA and ESR1 were identified at the time of progression [27]. $R B 1$ acquired mutations were observed only in patients receiving palbociclib plus fulvestrant (4.7\% of tumors), while mutations in PIK3CA and ESR1 were acquired in both treatment groups ( $8.2 \%$ and $12.8 \%$ of patients, respectively), particularly PIK3CA E542K and ESR1 Y537S and D538G mutations [27]. Existing therapeutic strategies after failure of CDK4/6i include chemotherapy, ET alone or ET combined with targeted agents. Targeting the PI3K/mTOR/AKT pathway, continuing CDK4/6i after progression, or new more powerful SERDs are among the therapeutic strategies currently being evaluated after CDK4/6i progression [19]. The potential clinical utility of testing targetable genomic alterations in ctDNA of patients with MBC was recently reported [58], but whether PIK3CA, $E S R 1, R B 1$ or alterations in other genes at the time of progression to CDK4/6i might help personalize subsequent therapeutic strategies remain to be established in future studies.

\section{The Role of Thymidine Kinase-1 Serum Activity}

Thymidine kinase 1 (TK1) is an enzyme involved in the DNA salvage pathway which catalyzes the phosphorylation of thymidine to the monophosphate form (dTMP), which is then further phosphorylated to deoxy thymidine triphosphate (dTTP) before being incorporated into DNA [59]. TK1 has also a crucial role in DNA damage repair, being essential in replacing the pool of dTTP in case of cellular DNA damage [59]. TK1 is expressed mainly in dividing cells, increasing during the G1-S phase and being degraded after cell division [59]. Therefore, it could be deemed as a marker of cell proliferation. Moreover, the synthesis of TK1 is regulated by the E2F transcription factors whose activation is regulated by $\mathrm{CDK} 4 / 6-\mathrm{Rb}$ pathway, suggesting a potential role for TK1 in monitoring the activity and efficacy of CDK4/6i [60].

Several studies showed the elevated levels of TK1 in many cancer types, including breast [61]. TK1 can be assessed in plasma or serum samples from patients with BC $[62,63]$ and levels of circulating TK1 activity (TKa), both at baseline and during treatments, were prognostic in ET-treated MBC patients [64,65].

The first report on serum TKa in patients treated with CDK4/6i derives from NeoPalAna, a pre-operative trial in which patients with stage II and III HR+/HER2 - BC received anastrozole alone, followed by palbociclib and anastrozole for four cycles, followed by the pre-surgical washout of palbociclib with the exception of eight patients in which the combination was received until surgery [20]. During treatment with anastrozole alone, there was no significant change in TKa, while a marked reduction was observed after two weeks from palbociclib initiation. During preoperative washout, TKa increased significantly, but remained low in those who continued palbociclib until surgery [28]. There was a high correlation between changes in serum TKa and tumor $\mathrm{Ki}-67$. These data suggested a pharmacodynamic role for serum TKa in palbociclib-treated patients [28].

The hypothesis that baseline TKa or early changes in TKa levels might be prognostic in patients with HR+/HER2 - MBC treated with CDK4/6i was then explored in TREnd [29]. In this trial, comparing the efficacy and safety of single-agent palbociclib vs. palbociclib plus the ET previously received for MBC, baseline TKa was not a poor prognostic factor. However, patients showing an increase in TKa after one month of treatment had a worse PFS compared to those without increase, suggesting TKa dynamics might have a role as an early marker of resistance to palbociclib [29].

The prognostic role of TKa was further evaluated in 103 plasma samples obtained from ER+/HER2- MBC patients treated with ET and palbociclib within ALCINA study [66]. In this study, baseline TKa was an independent poor prognostic marker of PFS and OS. Additionally, TKa at 4-week was associated with OS [66], while adding the changes in TKa at 4 weeks compared to baseline did not further increase prediction.

Lately, results from PYTHIA (NTC02536742), a biomarker discovery phase II singlearm study of fulvestrant and palbociclib in 122 women with HR+/HER2- MBC pro- 
gressing on prior ET, were presented [67]. TKa was assessed at baseline, after 15 days of treatment and before initiating cycle 2 . At each timepoint higher TKa was significantly and independently associated with PFS [67]. Interestingly, the group of patients who, at day 15, did not experience a drop in TKa below the limit of detection of the assay, suggesting an incomplete biomarker response, was enriched for patients with de novo resistance to palbociclib plus fulvestrant [67].

There is still uncertainty regarding the optimal method for quantifying TK1 levels and activity, the reproducibility or the optimal cut-off to be used. However, serum TKa can be easily measured through a peripheral blood draw and quantified via ELISA-based assays, thus representing a non-invasive and cost-effective way of estimating prognosis at baseline, as well as monitoring treatment response in patients with CDK4/6i-treated HR+/HER2MBC [68]. Additional studies are needed to establish its clinical utility.

\section{Additional Circulating Biomarkers}

CTCs are cancer cells found in the bloodstream after detaching from primary and/or metastatic tumors. Their concentration is usually very low making their detection quite challenging; despite this, the prognostic role of CTCs in patients with MBC was extensively demonstrated $[69,70]$. Additionally, molecular characterization of CTCs might increase their clinical validity [71]. The prognostic value of CTC was recently analyzed in patients enrolled in a translational sub-study of TREnd [30]. CTCs count after the first cycle of palbociclib (T1), but not at baseline was prognostic in terms of PFS. Additionally, the dynamics of CTCs count at T1 was prognostic. Indeed, patients with an increase of three or more CTCs at T1 experienced shorter PFS compared to those without increase. Intriguingly, patients whose CTCs showed detectable expression of RB1 at any timepoint had better, although not statistically significant, outcomes compared to those with undetectable levels [30].

Exosomes are micro-vesicles ranging $40-150 \mathrm{~nm}$ in size carrying proteins, RNA and DNA. They are actively released from cancer cells and can be found in patients' blood [72]. TK1, CDK4, CDK6 and CDK9 expression have been analyzed by ddPCR on RNA extracted from exosomes in 40 patients with HR+/HER2- MBC before the administration of palbociclib and ET (T0), and after 3 months of treatment (T1) [73]. CDK4 levels at T0 correlated with longer PFS, while a significant increase of TK1 and CDK9 at T1 compared to T0 was found in patients with progressive disease [73].

DNA methylation is an epigenetic phenomenon in which a methyl group is added to the fifth carbon of the cytosine residue by DNA methyltransferases (DNMTs), predominantly in a CpG dinucleotide context, and is associated with gene silencing [74]. A recent study tested the feasibility of characterizing the epigenetic status of ESR1 by assessing the methylation status of its two main promoters, namely prom $\mathrm{A}$ and promB, using methylation-specific ddPCR [75]. CtDNA from 49 women with HR+/HER2- MBC predominantly treated with CDK4/6i and ET was analyzed before starting treatment and after 3 months, at the time of restaging. While baseline methylation levels of both promA and promB were not associated with PFS, an increase in promB or in either promA or promB at restaging was associated with a significantly worse prognosis [75].

MiRNA are small non-coding RNAs that, by modulating specific target mRNA, might play a major role in physiological or pathological processes, including CDK4/6i resistance $[76,77]$. Indeed, miR-223 was shown to be a modulator of CDK4/6i response in vitro and in vivo [76], and the exosomal miR-432-5p has been implicated in resistance to CDK4/6i [77]. However, data on circulating miRNA in patients with HR+/HER2- BC treated with CDK4/6i is lacking.

\section{Conclusions}

Biomarkers are key to personalize medicine. Notwithstanding the significant and rigorous efforts that have been made to identify potential biomarkers of de novo or acquired resistance to CDK4/6i, none of the investigated markers has been implemented in the 
clinical practice yet. Research efforts are focusing on circulating biomarkers given their numerous advantages for both clinical development and application: they can be obtained non-invasively through a simple withdrawal of peripheral blood in virtually all patients with $\mathrm{MBC}$; they are easy to be repeated over time allowing real-time monitoring of therapy; they might be representative of all metastatic sites and genetic clones within a tumor. However, one of the main drawbacks in the development of circulating biomarkers includes their low concentrations, which challenges the creation of both sensitive and precise tests. Studies showed discrepant results probably due to the different technologies and methodologies used, the different study populations analyzed and possibly the type of CDK4/6i administered. Therefore, further studies are needed to identify clinically useful biomarkers of CDK4/6i response. Future efforts to address these issues must be made before circulating biomarkers might enter into the clinical management of patients with $\mathrm{HR}+$ /HER2 - MBC.

Author Contributions: Conceptualization, I.M., A.L. and L.M.; writing—original draft preparation, I.M., A.L. and L.M.; writing—review and editing, F.G., C.G., G.M.F., M.B., A.D.L. and L.B.; supervision, I.M and L.M.; funding acquisition, L.M. All authors have read and agreed to the published version of the manuscript.

Funding: This work was funded by Fondazione AIRC per la ricerca sul cancro (IG 22869 and MFAG 18880 to L Malorni and MFAG 14371 to I Migliaccio).

Institutional Review Board Statement: Not applicable.

Informed Consent Statement: Not applicable.

Data Availability Statement: Not applicable.

Acknowledgments: We would like to thank the Fondazione "Sandro Pitigliani" per la lotta contro i tumori ONLUS for its support.

Conflicts of Interest: I Migliaccio, A Leo, F Galardi, C Guarducci, GM Fusco: None; M Benelli: Consultant honoraria: Novartis; L Biganzoli: Personal financial interests (honoraria, consulting or advisory role): AstraZeneca, Celgene, Daiichi-Sankyo, Eisai, Genomic Health, Ipsen, Lilly, Novartis, Pfizer, Pierre Fabre, Roche, Takeda. Institutional financial interests: Celgene, Genomic Health, Novartis; A Di Leo: Personal financial interests (honoraria, consulting or advisory role): Amgen, AstraZeneca, Athenex, Bayer, Celgene, Daiichi-Sankyo, Eisai, Genentech, Genomic Health, Ipsen, Lilly, Novartis, Pfizer, Pierre Fabre, Puma Biotechnology, Roche, Seattle Genetics, Sellas Life Sciences Group. Institutional financial interests: Novartis; L. Malorni: Speaker/consultant honoraria: Novartis, Pfizer, Lilly. Research Grant: Novartis, Pfizer. The funders had no role in the design of the study; in the collection, analyses, or interpretation of data; in the writing of the manuscript, or in the decision to publish the results.

\section{References}

1. Migliaccio, I.; Malorni, L.; Hart, C.D.; Guarducci, C.; Di Leo, A. Endocrine therapy considerations in postmenopausal patients with hormone receptor positive, human epidermal growth factor receptor type 2 negative advanced breast cancers. BMC Med. 2015, 13, 46. [CrossRef]

2. Pan, H.; Gray, R.; Braybrooke, J.; Davies, C.; Taylor, C.; McGale, P.; Peto, R.; Pritchard, K.I.; Bergh, J.; Dowsett, M.; et al. 20-Year Risks of Breast-Cancer Recurrence after Stopping Endocrine Therapy at 5 Years. N. Engl. J. Med. 2017, 377, 1836-1846. [CrossRef]

3. Finn, R.S.; Crown, J.P.; Lang, I.; Boér, K.; Bondarenko, I.M.; Kulyk, S.O.; Ettl, J.; Patel, R.; Pinter, T.; Schmidt, M.; et al. The cyclin-dependent kinase $4 / 6$ inhibitor palbociclib in combination with letrozole versus letrozole alone as first-line treatment of oestrogen receptor-positive, HER2-negative, advanced breast cancer (PALOMA-1/TRIO-18): A randomised phase 2 study. Lancet Oncol. 2015, 16, 25-35. [CrossRef]

4. Turner, N.C.; Ro, J.; André, F.; Loi, S.; Verma, S.; Iwata, H.; Harbeck, N.; Loibl, S.; Bartlett, C.H.; Zhang, K.; et al. Palbociclib in Hormone-Receptor-Positive Advanced Breast Cancer. N. Engl. J. Med. 2015, 373, 209-219. [CrossRef] [PubMed]

5. Finn, R.S.; Martin, M.; Rugo, H.S.; Jones, S.; Im, S.-A.; Gelmon, K.; Harbeck, N.; Lipatov, O.N.; Walshe, J.M.; Moulder, S.; et al. Palbociclib and Letrozole in Advanced Breast Cancer. N. Engl. J. Med. 2016, 375, 1925-1936. [CrossRef]

6. Hortobagyi, G.N.; Stemmer, S.M.; Burris, H.A.; Yap, Y.S.; Sonke, G.S.; Paluch-Shimon, S.; Campone, M.; Blackwell, K.L.; André, F.; Winer, E.P.; et al. Ribociclib as First-Line Therapy for HR-Positive, Advanced Breast Cancer. N. Engl. J. Med. 2016, 375, 1738-1748. [CrossRef] [PubMed] 
7. Dickler, M.N.; Tolaney, S.M.; Rugo, H.S.; Cortés, J.; Diéras, V.; Patt, D.; Wildiers, H.; Hudis, C.A.; O’Shaughnessy, J.; Zamora, E.; et al. MONARCH 1, A Phase II Study of Abemaciclib, a CDK4 and CDK6 Inhibitor, as a Single Agent, in Patients with Refractory HR+/HER2- Metastatic Breast Cancer. Clin. Cancer Res. 2017, 23, 5218-5224. [CrossRef]

8. Goetz, M.P.; Toi, M.; Campone, M.; Sohn, J.; Paluch-Shimon, S.; Huober, J.; Park, I.H.; Trédan, O.; Chen, S.-C.; Manso, L.; et al. MONARCH 3: Abemaciclib As Initial Therapy for Advanced Breast Cancer. J. Clin. Oncol. 2017, 35, 3638-3646. [CrossRef] [PubMed]

9. Sledge, G.W., Jr.; Toi, M.; Neven, P.; Sohn, J.; Inoue, K.; Pivot, X.; Burdaeva, O.; Okera, M.; Masuda, N.; Kaufman, P.A.; et al. MONARCH 2: Abemaciclib in Combination With Fulvestrant in Women With HR+/HER2- Advanced Breast Cancer Who Had Progressed While Receiving Endocrine Therapy. J. Clin. Oncol. 2017, 35, 2875-2884. [CrossRef]

10. Slamon, D.J.; Neven, P.; Chia, S.; Fasching, P.A.; De Laurentiis, M.; Im, S.-A.; Petrakova, K.; Bianchi, G.V.; Esteva, F.J.; Martín, M.; et al. Phase III Randomized Study of Ribociclib and Fulvestrant in Hormone Receptor-Positive, Human Epidermal Growth Factor Receptor 2-Negative Advanced Breast Cancer: MONALEESA-3. J. Clin. Oncol. 2018, 36, 2465-2472. [CrossRef]

11. Tripathy, D.; Im, S.-A.; Colleoni, M.; Franke, F.; Bardia, A.; Harbeck, N.; Hurvitz, S.A.; Chow, L.; Sohn, J.; Lee, K.S.; et al. Ribociclib plus endocrine therapy for premenopausal women with hormone-receptor-positive, advanced breast cancer (MONALEESA-7): A randomised phase 3 trial. Lancet Oncol. 2018, 19, 904-915. [CrossRef]

12. Im, S.-A.; Lu, Y.-S.; Bardia, A.; Harbeck, N.; Colleoni, M.; Franke, F.; Chow, L.; Sohn, J.; Lee, K.-S.; Campos-Gomez, S.; et al. Overall Survival with Ribociclib plus Endocrine Therapy in Breast Cancer. N. Engl. J. Med. 2019, 381, 307-316. [CrossRef] [PubMed]

13. Sledge, G.W.; Toi, M.; Neven, P.; Sohn, J.; Inoue, K.; Pivot, X.; Burdaeva, O.; Okera, M.; Masuda, N.; Kaufman, P.A.; et al. The Effect of Abemaciclib Plus Fulvestrant on Overall Survival in Hormone Receptor-Positive, ERBB2-Negative Breast Cancer That Progressed on Endocrine Therapy-MONARCH 2. JAMA Oncol. 2020, 6, 116-124. [CrossRef] [PubMed]

14. Slamon, D.J.; Neven, P.; Chia, S.; Fasching, P.A.; De Laurentiis, M.; Im, S.-A.; Petrakova, K.; Bianchi, G.V.; Esteva, F.j.; Martín, M.; et al. Overall Survival with Ribociclib plus Fulvestrant in Advanced Breast Cancer. N. Engl. J. Med. 2020, 382, 514-524. [CrossRef]

15. Mayer, E.L.; Dueck, A.C.; Martin, M.; Rubovszky, G.; Burstein, H.J.; Bellet-Ezquerra, M.; Miller, K.D.; Zdenkowski, N.; Winer, E.P.; Pfeiler, G.; et al. Palbociclib with adjuvant endocrine therapy in early breast cancer (PALLAS): Interim analysis of a multicentre, open-label, randomised, phase 3 study. Lancet Oncol. 2021, 22, 212-222. [CrossRef]

16. Johnston, S.R.D.; Harbeck, N.; Hegg, R.; Toi, M.; Martin, M.; Shao, Z.M.; Zhang, Q.Y.; Rodriguez, J.L.M.; Campone, M.; Hamilton, E.; et al. Abemaciclib Combined With Endocrine Therapy for the Adjuvant Treatment of HR+, HER2-, Node-Positive, High-Risk, Early Breast Cancer (monarchE). J. Clin. Oncol. 2020, 38, 3987-3998. [CrossRef]

17. Guarducci, C.; Bonechi, M.; Boccalini, G.; Benelli, M.; Risi, E.; Di Leo, A.; Malorni, L.; Migliaccio, I. Mechanisms of Resistance to CDK4/6 Inhibitors in Breast Cancer and Potential Biomarkers of Response. Breast Care 2017, 12, 304-308. [CrossRef]

18. McCartney, A.; Migliaccio, I.; Bonechi, M.; Biagioni, C.; Romagnoli, D.; De Luca, F.; Galardi, F.; Risi, E.; De Santo, I.; Benelli, M.; et al. Mechanisms of Resistance to CDK4/6 Inhibitors: Potential Implications and Biomarkers for Clinical Practice. Front. Oncol. 2019, 9, 666. [CrossRef]

19. Migliaccio, I.; Bonechi, M.; McCartney, A.; Guarducci, C.; Benelli, M.; Biganzoli, L.; Di Leo, A.; Malorni, L. CDK4/6 Inhibitors: A Focus on Biomarkers of Response and Post-Treatment Therapeutic Strategies in Hormone Receptor-Positive HER2-Negative Breast Cancer. Cancer Treat. Rev. 2021, 93, 102136. [CrossRef] [PubMed]

20. Ma, C.X.; Gao, F.; Luo, J.; Northfelt, D.W.; Goetz, M.; Forero, A.; Hoog, J.; Naughton, M.; Ademuyiwa, F.; Suresh, R.; et al. NeoPalAna: Neoadjuvant Palbociclib, a Cyclin-Dependent Kinase 4/6 Inhibitor, and Anastrozole for Clinical Stage 2 or 3 Estrogen Receptor-Positive Breast Cancer. Clin. Cancer Res. 2017, 23, 4055-4065. [CrossRef] [PubMed]

21. Malorni, L.; Curigliano, G.; Minisini, A.; Cinieri, S.; Tondini, C.; D’Hollander, K.; Arpino, G.; Bernardo, A.; Martignetti, A.; Criscitiello, C.; et al. Palbociclib as single agent or in combination with the endocrine therapy received before disease progression for estrogen receptor-positive, HER2-negative metastatic breast cancer: TREnd trial. Ann. Oncol. 2018, 29, 1748-1754. [CrossRef]

22. Martin, M.; Zielinski, C.; Ruiz-Borrego, M.; Carrasco, E.; Turner, N.; Ciruelos, E.; Muñoz, M.; Bermejo, B.; Margeli, M.; Anton, A.; et al. Palbociclib in combination with endocrine therapy versus capecitabine in hormonal receptor-positive, human epidermal growth factor 2-negative, aromatase inhibitor-resistant metastatic breast cancer: A phase III randomised controlled trial-PEARL. Ann. Oncol. 2021, 32, 488-499. [CrossRef] [PubMed]

23. O'Leary, B.; Cutts, R.J.; Huang, X.; Hrebien, S.; Liu, Y.; André, F.; Loibl, S.; Loi, S.; Garcia-Murillas, I.; Cristofanilli, M.; et al. Circulating Tumor DNA Markers for Early Progression on Fulvestrant with or Without Palbociclib in ER+ Advanced Breast Cancer. J. Natl. Cancer Inst. 2021, 113, 309-317. [CrossRef] [PubMed]

24. Cristofanilli, M.; Turner, N.C.; Bondarenko, I.; Ro, J.; Im, S.-A.; Masuda, N.; Colleoni, M.; DeMichele, A.; Loi, S.; Verma, S.; et al. Fulvestrant plus palbociclib versus fulvestrant plus placebo for treatment of hormone-receptor-positive, HER2-negative metastatic breast cancer that progressed on previous endocrine therapy (PALOMA-3): Final analysis of the multicentre, double-blind, phase 3 randomised controlled trial. Lancet Oncol. 2016, 17, 425-439. [CrossRef] [PubMed]

25. Fribbens, C.; O’Leary, B.; Kilburn, L.; Hrebien, S.; Garcia-Murillas, I.; Beaney, M.; Cristofanilli, M.; Andre, F.; Loi, S.; Loibl, S.; et al. Plasma ESR1 Mutations and the Treatment of Estrogen Receptor-Positive Advanced Breast Cancer. J. Clin. Oncol. 2016, 34, 2961-2968. [CrossRef] [PubMed] 
26. O'Leary, B.; Hrebien, S.; Morden, J.P.; Beaney, M.; Fribbens, C.; Huang, X.; Liu, Y.; Bartlett, C.H.; Koehler, M.; Cristofanilli, M.; et al. Early circulating tumor DNA dynamics and clonal selection with palbociclib and fulvestrant for breast cancer. Nat. Commun. 2018, 9, 1-10. [CrossRef]

27. O'Leary, B.; Cutts, R.J.; Liu, Y.; Hrebien, S.; Huang, X.; Fenwick, K.; André, F.; Loibl, S.; Loi, S.; Garcia-Murillas, I.; et al. The Genetic Landscape and Clonal Evolution of Breast Cancer Resistance to Palbociclib plus Fulvestrant in the PALOMA-3 Trial. Cancer Discov. 2018, 8, 1390-1403. [CrossRef]

28. Bagegni, N.; Thomas, S.; Liu, N.; Luo, J.; Hoog, J.; Northfelt, N.W.; Goetz, M.P.; Forero, A.; Bergqvist, M.; Karen, J.; et al. Serum thymidine kinase 1 activity as a pharmacodynamic marker of cyclin-dependent kinase $4 / 6$ inhibition in patients with early-stage breast cancer receiving neoadjuvant palbociclib. Breast Cancer Res. 2017, 19, 123. [CrossRef]

29. McCartney, A.; Bonechi, M.; De Luca, F.; Biagioni, C.; Curigliano, G.; Moretti, E.; Minisini, A.M.; Bergqvist, M.; Benelli, M.; Migliaccio, I.; et al. Plasma Thymidine Kinase Activity as a Biomarker in Patients with Luminal Metastatic Breast Cancer Treated with Palbociclib within the TREnd Trial. Clin. Cancer Res. 2020, 26, 2131-2139. [CrossRef]

30. Galardi, F.; De Luca, F.; Biagioni, C.; Migliaccio, I.; Curigliano, G.; Minisini, A.M.; Bonechi, M.; Moretti, E.; Risi, E.; McCartney, A.; et al. Circulating tumor cells and palbociclib treatment in patients with ER-positive, HER2-negative advanced breast cancer: Results from a translational sub-study of the TREnd trial. Breast Cancer Res. 2021, 23. [CrossRef]

31. Tolaney, S.M.; Toi, M.; Neven, P.; Sohn, J.; Grischke, E.-M.; Llombart-Cussac, A.; Soliman, H.; Litchfield, L.M.; Wijayawardana, S.; Forrester, T.; et al. Abstract 4458: Clinical significance ofPIK3CAandESR1mutations in ctDNA and FFPE samples from the MONARCH 2 study of abemaciclib plus fulvestrant. Cancer Res. 2019, 79, 4458. [CrossRef]

32. Andre, F.; Su, F.; Solovieff, N.; Arteaga, C.L.; Hortobagyi, G.N.; Chia, S.K.L.; Neven, P.; Bardia, A.; Tripathy, D.; Lu, Y.-S.; et al. Pooled ctDNA analysis of the MONALEESA (ML) phase III advanced breast cancer (ABC) trials. J. Clin. Oncol. 2020, 38, 1009. [CrossRef]

33. Hortobagyi, G.; Stemmer, S.; Campone, M.; Sonke, G.; Arteaga, C.; Paluch-Shimon, S.; Petrakova, K.; Villanueva, C.; Nusch, A.; Grischke, E.-M.; et al. Abstract PD4-06: First-line ribociclib + letrozole in hormone receptor-positive, HER2-negative advanced breast cancer: Efficacy by baseline circulating tumor DNA alterations in MONALEESA-2. Cancer Res. 2018, 78, PD4-06. [CrossRef]

34. Neven, P.; Petrakova, K.; Bianchi, G.V.; De La Cruz-Merino, L.; Jerusalem, G.; Sonke, G.; Nusch, A.; Beck, J.; Chia, S.; Solovieff, N.; et al. Abstract PD2-05: Biomarker analysis by baseline circulating tumor DNA alterations in the MONALEESA-3 study. Cancer Res. 2019, 79, PD2-05. [CrossRef]

35. Tay, T.K.Y.; Tan, P.H. Liquid Biopsy in Breast Cancer: A Focused Review. Arch. Pathol. Lab. Med. 2020. [CrossRef] [PubMed]

36. Galardi, F.; De Luca, F.; Romagnoli, D.; Biagioni, C.; Moretti, E.; Biganzoli, L.; Di Leo, A.; Migliaccio, I.; Malorni, L.; Benelli, M. Cell-Free DNA-Methylation-Based Methods and Applications in Oncology. Biomolecules 2020, 10, 1677. [CrossRef]

37. Stover, D.; Parsons, H.A.; Ha, G.; Freeman, S.; Barry, W.T.; Guo, H.; Choudhury, A.D.; Gydush, G.; Reed, S.C.; Rhoades, J.; et al. Association of Cell-Free DNA Tumor Fraction and Somatic Copy Number Alterations with Survival in Metastatic Triple-Negative Breast Cancer. J. Clin. Oncol. 2018, 36, 543-553. [CrossRef]

38. Henley, S.A.; Dick, F.A. The retinoblastoma family of proteins and their regulatory functions in the mammalian cell division cycle. Cell Div. 2012, 7, 10. [CrossRef] [PubMed]

39. Herrera-Abreu, M.T.; Palafox, M.; Asghar, U.; Rivas, M.A.; Cutts, R.J.; Garcia-Murillas, I.; Pearson, A.; Guzman, M.; Rodriguez, O.; Grueso, J.; et al. Early Adaptation and Acquired Resistance to CDK4/6 Inhibition in Estrogen Receptor-Positive Breast Cancer. Cancer Res. 2016, 76, 2301-2313. [CrossRef]

40. Guarducci, C.; Bonechi, M.; Benelli, M.; Biagioni, C.; Boccalini, G.; Romagnoli, D.; Verardo, R.; Schiff, R.; Osborne, C.K.; De Angelis, C.; et al. Cyclin E1 and Rb modulation as common events at time of resistance to palbociclib in hormone receptor-positive breast cancer. Npj Breast Cancer 2018, 4, 38. [CrossRef]

41. Taylor-Harding, B.; Aspuria, P.-J.; Agadjanian, H.; Cheon, D.-J.; Mizuno, T.; Greenberg, D.; Allen, J.R.; Spurka, L.; Funari, V.; Spiteri, E.; et al. Cyclin E1 and RTK/RAS signaling drive CDK inhibitor resistance via activation of E2F and ETS. Oncotarget 2014, 6, 696-714. [CrossRef] [PubMed]

42. De Laurentiis, M.; Malorni, L.; Bianchini, G.; Caputo, R.; Giuliano, M.; Zambelli, A.; Puglisi, F.; Del Mastro, L.; Colleoni, M.; Montemurro, F.; et al. Abstract P5-01-07: Bioitalee-Biomarker analysis on liquid biopsies of patients treated with ribociclib and letrozole as first-line therapy for advanced breast cancer (aBC) (NCT03439046). Cancer Res. 2020, 80, P5-01. [CrossRef]

43. Razavi, P.; Chang, M.T.; Xu, G.; Bandlamudi, C.; Ross, D.S.; Vasan, N.; Cai, Y.; Bielski, C.M.; Donoghue, M.T.A.; Jonsson, P.; et al. The Genomic Landscape of Endocrine-Resistant Advanced Breast Cancers. Cancer Cell 2018, 34, 427-438.e6. [CrossRef] [PubMed]

44. Vora, S.R.; Juric, D.; Kim, N.; Mino-Kenudson, M.; Huynh, T.; Costa, C.; Lockerman, E.L.; Pollack, S.F.; Liu, M.; Li, X.; et al. CDK 4/6 Inhibitors Sensitize PIK3CA Mutant Breast Cancer to PI3K Inhibitors. Cancer Cell 2014, 26, 136-149. [CrossRef] [PubMed]

45. Zhang, J.; Xu, K.; Liu, P.; Geng, Y.; Wang, B.; Gan, W.; Guo, J.; Wu, F.; Chin, Y.R.; Berrios, C.; et al. Inhibition of Rb Phosphorylation Leads to mTORC2-Mediated Activation of Akt. Mol. Cell 2016, 62, 929-942. [CrossRef]

46. Jansen, V.M.; Bhola, N.E.; Bauer, J.A.; Formisano, L.; Lee, K.-M.; Hutchinson, K.E.; Witkiewicz, A.K.; Moore, P.D.; Estrada, M.V.; Sánchez, V;; et al. Kinome-Wide RNA Interference Screen Reveals a Role for PDK1 in Acquired Resistance to CDK4/6 Inhibition in ER-Positive Breast Cancer. Cancer Res. 2017, 77, 2488-2499. [CrossRef]

47. Michaloglou, C.; Crafter, C.; Siersbaek, R.; Delpuech, O.; Curwen, J.O.; Carnevalli, L.; Staniszewska, A.D.; Polanska, U.M.; CheraghchiBashi, A.; Lawson, M.; et al. Combined Inhibition of mTOR and CDK4/6 Is Required for Optimal Blockade of E2F Function and Long-term Growth Inhibition in Estrogen Receptor-positive Breast Cancer. Mol. Cancer Ther. 2018, 17, 908-920. [CrossRef] 
48. Wander, S.A.; Cohen, O.; Gong, X.; Johnson, G.N.; Buendia-Buendia, J.E.; Lloyd, M.R.; Kim, D.; Luo, F.; Mao, P.; Helvie, K.; et al. The Genomic Landscape of Intrinsic and Acquired Resistance to Cyclin-Dependent Kinase 4/6 Inhibitors in Patients with Hormone Receptor-Positive Metastatic Breast Cancer. Cancer Discov. 2020, 10, 1174-1193. [CrossRef]

49. Costa, C.; Wang, Y.; Ly, A.; Hosono, Y.; Murchie, E.; Walmsley, C.S.; Huynh, T.; Healy, C.; Peterson, R.; Yanase, S.; et al. PTEN Loss Mediates Clinical Cross-Resistance to CDK4/6 and PI3K $\alpha$ Inhibitors in Breast Cancer. Cancer Discov. 2019, 10, 72-85. [CrossRef]

50. Juric, D.; Castel, P.; Griffith, M.; Griffith, O.L.; Won, H.H.; Ellis, H.; Ebbesen, S.H.; Ainscough, B.; Ramu, A.; Iyer, G.; et al. Convergent loss of PTEN leads to clinical resistance to a PI(3)K $\alpha$ inhibitor. Nat. Cell Biol. 2015, 518, 240-244. [CrossRef]

51. Razavi, P.; Dickler, M.N.; Shah, P.D.; Toy, W.; Brown, D.N.; Won, H.H.; Li, B.T.; Shen, R.; Vasan, N.; Modi, S.; et al. Alterations in PTEN and ESR1 promote clinical resistance to alpelisib plus aromatase inhibitors. Nat. Rev. Cancer 2020, 1, 382-393. [CrossRef] [PubMed]

52. Smyth, L.M.; Tamura, K.; Oliveira, M.; Ciruelos, E.M.; Mayer, I.A.; Sablin, M.-P.; Biganzoli, L.; Ambrose, H.J.; Ashton, J.; Barnicle, A.; et al. Capivasertib, an AKT Kinase Inhibitor, as Monotherapy or in Combination with Fulvestrant in Patients with AKT1E17K-Mutant, ER-Positive Metastatic Breast Cancer. Clin. Cancer Res. 2020, 26, 3947-3957. [CrossRef] [PubMed]

53. De Santo, I.; McCartney, A.; Migliaccio, I.; Di Leo, A.; Malorni, L. The Emerging Role of ESR1 Mutations in Luminal Breast Cancer as a Prognostic and Predictive Biomarker of Response to Endocrine Therapy. Cancers 2019, 11, 1894. [CrossRef]

54. Bidard, F.C.; Callens, C.; Dalenc, F.; Pistilli, B.; Rouge, T.D.L.M.; Clatot, F.; D’Hondt, V.; Teixeira, L.; Vegas, H.; Everhard, S.; et al. Prognostic impact of ESR1 mutations in ER+ HER2- MBC patients prior treated with first line AI and palbociclib: An exploratory analysis of the PADA-1 trial. J. Clin. Oncol. 2020, 38, 1010. [CrossRef]

55. Formisano, L.; Lu, Y.; Servetto, A.; Hanker, A.B.; Jansen, V.M.; Bauer, J.A.; Sudhan, D.R.; Guerrero-Zotano, A.L.; Croessmann, S.; Guo, Y.; et al. Aberrant FGFR signaling mediates resistance to CDK4/6 inhibitors in ER+ breast cancer. Nat. Commun. 2019, 10, 1-14. [CrossRef] [PubMed]

56. Darrigues, L.; Pierga, J.-Y.; Bernard-Tessier, A.; Bièche, I.; Silveira, A.B.; Michel, M.; Loirat, D.; Cottu, P.; Cabel, L.; Dubot, C.; et al. Circulating tumor DNA as a dynamic biomarker of response to palbociclib and fulvestrant in metastatic breast cancer patients. Breast Cancer Res. 2021, 23. [CrossRef]

57. Martínez-Sáez, O.; Pascual, T.; Brasó-Maristany, F.; Chic, N.; González-Farré, B.; Sanfeliu, E.; Rodríguez, A.; Martínez, D.; Galván, P.; Rodríguez, A.B.; et al. Circulating tumor DNA dynamics in advanced breast cancer treated with CDK4/6 inhibition and endocrine therapy. NPJ Breast Cancer 2021, 7, 8. [CrossRef]

58. Turner, N.C.; Kingston, B.; Kilburn, L.S.; Kernaghan, S.; Wardley, A.M.; Macpherson, I.R.; Baird, R.D.; Roylance, R.; Stephens, P.; Oikonomidou, O.; et al. Circulating tumour DNA analysis to direct therapy in advanced breast cancer (plasmaMATCH): A multicentre, multicohort, phase 2a, platform trial. Lancet Oncol. 2020, 21, 1296-1308. [CrossRef]

59. Bitter, E.E.; Townsend, M.H.; Erickson, R.; Allen, C.; O'Neill, K.L. Thymidine kinase 1 through the ages: A comprehensive review. Cell Biosci. 2020, 10, 1-16. [CrossRef]

60. Sherley, J.L.; Kelly, T.J. Regulation of human thymidine kinase during the cell cycle. J. Biol. Chem. 1988, 263, 8350-8358. [CrossRef]

61. Alegre, M.M.; Robison, R.A.; O'Neill, K.L. Thymidine Kinase 1 Upregulation Is an Early Event in Breast Tumor Formation. J. Oncol. 2012, 2012. [CrossRef]

62. Robertson, J.F.; O’Neill, K.L.; Thomas, M.W.; McKenna, P.G.; Blamey, R.W. Thymidine kinase in breast cancer. Br. J. Cancer 1990, 62, 663-667. [CrossRef]

63. Broët, P.; Romain, S.; Daver, A.; Ricolleau, G.; Quillien, V.; Rallet, A.; Asselain, B.; Martin, P.; Spyratos, F. Thymidine Kinase as a Proliferative Marker: Clinical Relevance in 1692 Primary Breast Cancer Patients. J. Clin. Oncol. 2001, 19, 2778-2787. [CrossRef]

64. Bonechi, M.; Galardi, F.; Biagioni, C.; De Luca, F.; Bergqvist, M.; Neumüller, M.; Guarducci, C.; Boccalini, G.; Gabellini, S.; Migliaccio, I.; et al. Plasma thymidine kinase-1 activity predicts outcome in patients with hormone receptor positive and HER2 negative metastatic breast cancer treated with endocrine therapy. Oncotarget 2018, 9, 16389-16399. [CrossRef]

65. McCartney, A.; Biagioni, C.; Schiavon, G.; Bergqvist, M.; Mattsson, K.; Migliaccio, I.; Benelli, M.; Romagnoli, D.; Bonechi, M.; Boccalini, G.; et al. Prognostic role of serum thymidine kinase 1 activity in patients with hormone receptor-positive metastatic breast cancer: Analysis of the randomised phase III Evaluation of Faslodex versus Exemestane Clinical Trial (EFECT). Eur. J. Cancer 2019, 114, 55-66. [CrossRef] [PubMed]

66. Cabel, L.; Rosenblum, D.; Lerebours, F.; Brain, E.; Loirat, D.; Bergqvist, M.; Cottu, P.; Donnadieu, A.; Bethune, A.; Kiavue, N.; et al. Plasma thymidine kinase 1 activity and outcome of ER+ HER2 - metastatic breast cancer patients treated with palbociclib and endocrine therapy. Breast Cancer Res. 2020, 22, 98. [CrossRef]

67. Malorni, L.; Tyekucheva, S.; Hilbers, F.S.; Ignatiadis, M.; Neven, P.; Colleoni, M.; Henry, S.; Ballestrero, A.; Bonetti, A.; Jerusalem, G.; et al. Abstract PS5-05: Serum thymidine kinase activity in patients with luminal metastatic breast cancer treated with palbociclib and fulvestrant within the PYTHIA trial. Cancer Res. 2021, 81, PS5-05. [CrossRef]

68. McCartney, A.; Malorni, L. Potential through Simplicity: Thymidine Kinase-1 as a Biomarker for CDK4/6 Inhibitors. Br. J. Cancer 2020, 123, 176-177. [CrossRef]

69. Cristofanilli, M.; Budd, G.T.; Ellis, M.J.; Stopeck, A.; Matera, J.; Miller, M.C.; Reuben, J.M.; Doyle, G.V.; Allard, W.J.; Terstappen, L.W.; et al. Circulating Tumor Cells, Disease Progression, and Survival in Metastatic Breast Cancer. N. Engl. J. Med. 2004, 351, 781-791. [CrossRef] [PubMed] 
70. Bidard, F.-C.; Peeters, D.J.; Fehm, T.; Nolé, F.; Gisbert-Criado, R.; Mavroudis, D.; Grisanti, S.; Generali, D.; Garcia-Saenz, J.A.; Stebbing, J.; et al. Clinical validity of circulating tumour cells in patients with metastatic breast cancer: A pooled analysis of individual patient data. Lancet Oncol. 2014, 15, 406-414. [CrossRef]

71. Kwan, T.; Bardia, A.; Spring, L.M.; Giobbie-Hurder, A.; Kalinich, M.; Dubash, T.; Sundaresan, T.; Hong, X.; Licausi, J.A.; Ho, U.; et al. A Digital RNA Signature of Circulating Tumor Cells Predicting Early Therapeutic Response in Localized and Metastatic Breast Cancer. Cancer Discov. 2018, 8, 1286-1299. [CrossRef]

72. Liu, T.; Hooda, J.; Atkinson, J.M.; Whiteside, T.L.; Oesterreich, S.; Lee, A.V. Exosomes in Breast Cancer-Mechanisms of Action and Clinical Potential. Mol. Cancer Res. 2021. [CrossRef] [PubMed]

73. Del Re, M.; Bertolini, I.; Crucitta, S.; Fontanelli, L.; Rofi, E.; De Angelis, C.; Diodati, L.; Cavallero, D.; Gianfilippo, G.; Salvadori, B.; et al. Overexpression of TK1 and CDK9 in plasma-derived exosomes is associated with clinical resistance to CDK4/6 inhibitors in metastatic breast cancer patients. Breast Cancer Res. Treat. 2019, 178, 57-62. [CrossRef] [PubMed]

74. Suzuki, M.M.; Bird, A. DNA methylation landscapes: Provocative insights from epigenomics. Nat. Rev. Genet. 2008, 9, 465-476. [CrossRef] [PubMed]

75. Gerratana, L.; Basile, D.; Franzoni, A.; Allegri, L.; Viotto, D.; Corvaja, C.; Bortot, L.; Bertoli, E.; Buriolla, S.; Targato, G.; et al. Plasma-Based Longitudinal Evaluation of ESR1 Epigenetic Status in Hormone Receptor-Positive HER2-Negative Metastatic Breast Cancer. Front. Oncol. 2020, 10. [CrossRef] [PubMed]

76. Citron, F.; Segatto, I.; Vinciguerra, G.L.R.; Musco, L.; Russo, F.; Mungo, G.; D’Andrea, S.; Mattevi, M.C.; Perin, T.; Schiappacassi, M.; et al. Downregulation of miR-223 Expression Is an Early Event during Mammary Transformation and Confers Resistance to CDK4/6 Inhibitors in Luminal Breast Cancer. Cancer Res. 2019, 80, 1064-1077. [CrossRef] [PubMed]

77. Cornell, L.; Wander, S.A.; Visal, T.; Wagle, N.; Shapiro, G.I. MicroRNA-Mediated Suppression of the TGF- $\beta$ Pathway Confers Transmissible and Reversible CDK4/6 Inhibitor Resistance. Cell Rep. 2019, 26, 2667-2680.e7. [CrossRef] 